\title{
PLANEJAMENTO E AVALIAÇÃO: Conexões entre o PDI, o Programa de Gestão Universitária e a Avaliação Institucional no âmbito da Universidade do Estado da Bahia
}

\begin{abstract}
IVAN LUIZ NOVAES
Universidade do Estado da Bahia. Doutor em Educação $(\mathrm{PhD})$ - Université de Sherbrooke - Canadá. Professor dos Programas de Pós-graduação stricto sensu Gestão e Tecnologias Aplicadas à Educação - GESTEC - e Educação e Contemporaneidade - PPGEduc -, ambos vinculados ao Departamento de Educação Campus I da Universidade do Estado da Bahia

- Uneb. Coordenador do Grupo de Pesquisa Gestão Educacional e Formação de Gestores NUGEF/CNPQ. Assessor Especial do Gabinete da Reitoria da Universidade Estadual da Bahia - Uneb, coordenador da Secretaria Especial de Avaliação Institucional - SEAVI. OrcIC: https:// orcid.org/0000-0003-2607-2304 E-mail: ilnovaes@uneb.br
\end{abstract}




\section{LIDIA BOAVENTURA PIMENTA}

Universidade do Estado da Bahia. Doutora em Educação, exerce atividade de ensino nas áreas de Gestão de Organizações; Planejamento e Orçamento Público. Professora permanente e Vicecoordenadora do Programa de Pós-Graduação stricto sensu Gestão e Tecnologias Aplicadas à Educação - GESTEC -, na Universidade do Estado da Bahia. Pesquisadora do Grupo de Pesquisa Educação, Universidade e Região -EDUReg. Pró-Reitora de Planejamento desta Universidade. E-mail: lpimenta@uneb.br

\section{RESUMO}

Este artigo explora o planejamento e a avaliação no contexto da educação superior, com ênfase em conexões entre ambos para efeito de condução da gestão universitária. Abordamos a recente experiência da Universidade do Estado da Bahia (Uneb), na atualização do seu Plano de Desenvolvimento Institucional (PDI 2017 - 2022), a implantação e implementação do Programa de Gestão Universitária (ProGest 2018 - 2021) e suas conexões com os mecanismos de avaliação institucional utilizados nesta Universidade. A partir de alguns questionamentos, balizamos nossas reflexões com intuito de contribuir para estudos acerca dessa temática. Assim, partimos do pressuposto de que há estreitas conexões entre planejamento e avaliação no campo da gestão universitária. Isso nos levou à seguinte indagação: como os indicadores utilizados no processo de avaliação da educação superior podem subsidiar a elaboração do Plano de Desenvolvimento Institucional (PDI) da Universidade do Estado da Bahia? Utilizamos uma análise sucinta da legislação nacional e local acerca dessa temática, de modo a conduzir este estudo e apresentar, de maneira concisa, a experiência da Uneb na articulação entre o Plano de Desenvolvimento Institucional e o Programa de Gestão e seus mecanismos de avaliação.

Palavras-chave: Planejamento. Avaliação. Educação Superior. Gestão Universitária.

\section{O PLANNING AND EVALUATION: connections between the PDI, the University Management Program and the Institutional Evaluation within the State University of Bahia}

This article explores planning and evaluation in the context of higher education, with emphasis on connections between both for the purpose of conducting university management. We address the recent experience of the State University of Bahia (Uneb), the updating of its Institutional Development Plan (PDI 2017-2022), the implementation of the University Management Program (ProGest 2018-2021) and its connections with the mechanisms of institutional evaluation developed at this University. Our inquiry focused on reflections aimed at contributing to studies about this theme. Thus, we assume that there are close connections between planning and evaluation in the field of university management. This led us to the following question: how can the indicators used in the evaluation process of higher education subsidize the elaboration of the Institutional Development Plan (PDI) of the State University of Bahia? We use a 
brief analysis of national and local legislation on this subject in order to conduct this study and present, in a concise way, the experience of Uneb in the articulation between the Institutional Development Plan and the Management Program and its mechanisms of evaluation.

Keywords: Planning. Evaluation. Higher Education. University Management.

PLANIFICACIÓN Y EVALUACÓN: conexiones entre el PDI, el Programa de Gestión Universitaria y la Evaluación Institucional en el ámbito de la Universidad del Estado de Bahía

Este artículo explora la planificación y la evaluación en el contexto de la educación superior, con énfasis en conexiones entre ambos para efecto de conducción de la gestión universitaria. En la actualización de su Plan de Desarrollo Institucional (PDI 2017 - 2022), la implantación e implementación del Programa de Gestión Universitaria (ProGest 2018 - 2021) y sus conexiones con los mecanismos de evaluación institucional utilizados en esta Universidad. A partir de algunos cuestionamientos, balizamos nuestras reflexiones con el propósito de contribuir a estudios acerca de esta temática. Así, partimos del supuesto de que hay estrechas conexiones entre planificación y evaluación en el campo de la gestión universitaria. Esto nos llevó a la siguiente indagación: ¿cómo los indicadores utilizados en el proceso de evaluación de la educación superior pueden subsidiar la elaboración del Plan de Desarrollo Institucional (PDI) de la Universidad del Estado de Bahía? Utilizamos un análisis sucinta de la legislación nacional y local sobre esta temática, para llevar a cabo este estudio y presentar de manera concisa la experiencia de la Uneb en la articulación entre el Plan de Desarrollo Institucional y el Programa de Gestión y sus mecanismos de evaluación.

Palabras claves: Planificación. Evaluación. Educación universitaria. Gestión Universitaria.

\section{PLANEJAMENTO E AVALIAÇÃO: Conexões entre o PDI, o programa de Gestão Universitária e a Avaliação Institucional no âmbito da Universidade do Estado da Bahia}

\section{Introdução}

O planejamento e a avaliação, como ações integradas às políticas públicas para a educação superior no Brasil, se constituem, na atualidade, objeto de análises com o qual estudos e pesquisas exploram principais controvérsias, problemas e apontam estratégias para a sua melhor aplicação no âmbito das universidades. O resultado dessas análises nos permite considerar que, em torno 
do planejamento e da avaliação no âmbito da educação superior, há uma considerável produção técnica e científica cujo teor contribui para aprofundar o conhecimento sobre esses conceitos, bem como subsidiar a sua aplicabilidade.

Em termos de aplicabilidade, o planejamento, cujo produto se materializa em um plano e na sua execução, abrange um conjunto de fatores com os quais a sua efetivação, por vias meramente formais e protocolares, não se traduzirá em eficiência. Com o apoio nos estudos realizados por Matias-Pereira (2010) e Luz (2014), observa-se que o planejamento se constitui em um processo dinâmico e não se limita á concepção de um plano.

O mesmo ocorre com a avaliação, cuja efetivação se expressa na definição de critérios, indicadores, análise de dados e geração de informações. Cabe, todavia, remarcar que as complexas demandas em torno do planejamento e da avaliação, bem como as possibilidades do uso das tecnologias da informação, passaram a requerer certo grau de conhecimento técnico.

No mesmo nível de importância, se encontra a imperativa compreensão do intricado cenário que envolve as políticas de planejamento e avaliação para a educação superior. Compreendê-las implica, de um lado, incluir na esfera de análise, as políticas que são geradas pelos organismos internacionais e seus efeitos nas políticas nacionais. De outro, impõe-se o entendimento sobre as possíveis conexões entre as políticas de planejamento e de avaliação brasileira.

No primeiro caso, a alusão decorre da influência que tais políticas exercem sobre as políticas públicas nacionais destinadas a educação superior. No segundo, emana da necessidade de entender as conexões entre planejamento e a avaliação nesse novo cenário, onde tais políticas se tornaram obrigatórias no âmbito das instituições de educação superior.

Do ponto de vista teórico, é possível reconhecer linhas de conexão entre o planejamento e a avaliação e estabelecer diversos mecanismos de interação entre ambos, especialmente, quando se utiliza esses conceitos no campo da Educação.

Deste modo, cabe estabelecer alguns questionamentos acerca das possíveis conexões entre planejamento e avaliação no âmbito da educação superior, considerando a possibilidade de contribuir com os estudos nesse campo. A utilização de questionamentos pode apoiar trabalhos de pesquisas, como também balizar o desenvolvimento deste trabalho. Partindo do pressuposto no qual existem estreitas conexões entre ambos, cabe-nos indagar, como a legislação relativa à educação superior brasileira assegura essa relação? Questão que abordaremos à frente.

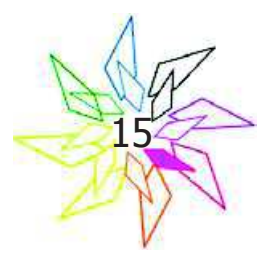


Podemos, ainda, apresentar como questionamento, de que maneira os indicadores utilizados no processo de avaliação da educação superior podem subsidiar a elaboração do Plano de Desenvolvimento Institucional (PDI) da Universidade do Estado da Bahia? Neste caso, cabenos sugerir possíveis estudos que apresentem como objetivo, identificar a relação entre indicadores da avaliação institucional e o processo de planejamento da UNEB. Para tal fim, aconselhamos adotar como referência o Plano de Desenvolvimento Institucional (PDI) e o Programa de Gestão para um período de 2018 a 2021.

Para esse tipo de estudo, indicamos uma abordagem de natureza descritiva, que tem por base a interpretação e descrição da realidade, sem qualquer interferência por parte dos autores no objeto de estudo. Em atenção ao que menciona Sylvia Roesch (1999), a partir do objetivo estabelecido é possível delinear a metodologia, quanto à natureza, bem como a abordagem, neste caso sob a perspectiva qualitativa, que envolve a obtenção de dados descritivos, coletados no contato direto do pesquisador com a situação estudada (GIL, 2002).

No que concerne ao primeiro questionamento, é possível observar que planejamento e avaliação no campo da educação não são algo muito recente. A inserção do planejamento na legislação, por exemplo, se apresenta desde a Constituição Federal de 1934, quando esta Lei atribui à União a responsabilidade de fixar um Plano Nacional de E ducação de maneira a abranger todos os graus de ensino. Cabe sublinhar que, a partir desta Constituição, o planejamento passou a integrar as demais Cartas Magnas, com exceção da Constituição de 1937 (PARENTE, 2001).

\section{Considerações gerais sobre planejamento}

Recentemente, na década de 90 do século passado, o planejamento adquiriu grande evidência no campo da educação se constituindo em um fenômeno de abrangência nacional e internacional. Nesta década a União, os estados e os municípios forma instados pelos órgãos oficiais a desenvolverem de planos de educação para seus respectivos sistemas de ensino. Tal fenômeno teve amparo legal na Constituição Federal de 1988, cujo artigo 214 preconiza,

A lei estabelecerá o plano nacional de educação, de duração decenal, com o objetivo de articular o sistema nacional de educação em regime de colaboração e definir diretrizes, objetivos, metas e estratégias de implementação para assegurar a manutenção e desenvolvimento do ensino em seus diversos níveis, etapas e modalidades... (BRASIL, 1988). 
É importante destacar que na mencionada época o fenômeno do planejamento no campo da educação ocorreu em escala mundial. Essa afirmação se apoia em análise sobre as iniciativas produzidas pelos organismos internacionais, tais como: a Conferência de Jontiem, apoiada pela Organização das Nações Unidas para a Educação, a Ciência e a Cultura (Unesco), Banco Mundial e Comissão Econômica para a América Latina (Cepal), bem como o Congresso Internacional Planeamiento y Gestión del Desarrollo de la Educación em 1990.

A repercussão dessas iniciativas internacionais se materializa no compromisso assumido pelo Brasil em alinhamento suas políticas educacionais às resoluções estabelecidas na Conferência Mundial de Educação Para Todos e a consequente elaboração do Plano Decenal de Educação para Todos (1993-2003).

O processo de planejamento é aqui entendido como a racionalização para definir objetivos e determinar meios, através de decisões e ações (SILVA, 2011); portanto, compreendemos que o planejamento antecederá à realização das ações. Para a implementação do processo de planejamento em uma organização é importante estipular as metas e prescrever o que fazer, quando, com que meios e como, para o alcance dos objetivos estabelecidos. (Valeriano, 1998). A expressão racional é usada como indicação do raciocínio lógico, utilizado na alocação dos recursos disponíveis, visando alcançar os objetivos da organização, ressaltando-se que o racional contrapõe-se à intuição e à improvisação, fatores que também se fazem presentes no processo de tomada de decisão.

O planejamento em uma organização, entendendo neste estudo a instituição universitária, segundo Silva (1996), deve ser concebido em etapas: (i) diagnóstico da situação existente em todas as áreas, tanto finalística, quanto na área meio; (ii) identificação da necessidade de bens e serviços; (iii) definição dos objetivos para as ações a serem desenvolvidas; discriminação e quantificação de metas e seus custos; (iv) avaliação dos resultados obtidos, subsidiando, assim, a alimentação da nova fase do processo. Todo o planejamento acontece de maneira integrada, pela qual, os órgãos integrantes da estrutura organizacional, atuam de forma comprometida, observando as metas previstas para sua área de atuação.

Desse modo, este instrumento de gestão procura cumprir as seguintes funções: apoiar o processo decisório; aportar maior racionalidade às decisões; e orientar as ações na instituição. $\mathrm{O}$ produto do processo de planejamento constitui-se no plano, caracterizando-se como instru-

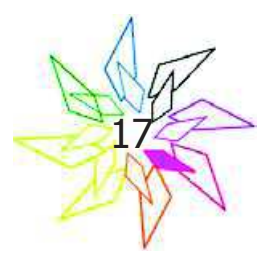


mento norteador para o desenvolvimento das ações nas diferentes áreas e níveis da organização (MEYER JR., 1988).

Este instrumento apresenta à comunidade quais os objetivos determinados, as metas estabelecidas e os custos para um período específico e a maneira como os seus diversos órgãos irão atuar, identificando seus respectivos níveis de responsabilidade na ação que será desenvolvida. Sem tal orientação, será difícil coordenar e convergir qualquer esforço em direção aos objetivos e metas estabelecidas.

\section{Considerações gerais sobre avaliação}

O que tange a avaliação, podemos observar que se trata de fenômeno relativamente recente na legislação brasileira, considerando que os textos normativos não faziam claras alusões à avaliação no campo da educação, sobretudo quando se tratava da educação superior. É a partir da Constituição Federal de 1988 que avalição adquire forma de orientação e designação normativa para os sistemas educacionais brasileiros.

A referida Constituição Carta de 1988, em seu Art.209, I e II apresenta de forma expressa que "o ensino é livre à iniciativa privada", observando-se o "cumprimento das normas gerais da educação nacional" e a "autorização e avaliação de qualidade pelo poder público" (BRASIL,1998) (grifos nossos).

Do ponto de vista normativo, a avaliação ganha contornos mais definidos a partir da implantação da Lei de Diretrizes e Bases da Educação Nacional (BRASIL, 1996). Está Lei, atribui, em seu Artigo $8^{\circ}$, incumbências à União para estabelecer processo nacional de avaliação do rendimento escolar no ensino Fundamental, Médio e Superior. Indica, ainda, que tal processo deve ocorrer em colaboração com os sistemas de ensino, a fim de assegurar prioridades e a melhoria da qualidade do ensino, por meio de processo nacional de avaliação das instituições de Educação Superior. Aqui está implicada a avaliação de cursos das IES por meio do acesso aos dados e informações concernentes a instituição de ensino da educação básica e superior (BRASIL, 1996, artigo $9^{\circ}$, incisos VI, VIII, $\S 2^{\circ}$ ).

Imprime-se, assim, uma política de avaliação dos sistemas educacionais. No caso em tela, trata-se da implementação de mecanismos de acompanhamento e regulação do sistema de educação superior, utilizando-se de mecanismos de avaliação do referido sistema. Delineiam- 
se, assim, as bases sobre as quais a LDB procura estabelecer conexões entre os mecanismos de planejamento, gestão e avaliação institucional.

Com efeito, o delineamento da avaliação no âmbito da educação superior se consolida a partir da Lei $n^{\circ} 10.861 / 04$, responsável por instituir o Sistema Nacional de Avaliação do Ensino Superior (SINAES). Em seu Artigo $2^{\circ}$, esta Lei se designa a promover a avaliação de instituições, de cursos e de desempenho dos estudantes, de maneira a assegurar,

I - avaliação institucional, interna e externa, contemplando a análise global e integrada das dimensões, estruturas, relações, compromisso social, atividades, finalidades e responsabilidades sociais das instituições de educação superior e de seus cursos;

II - o caráter público de todos os procedimentos, dados e resultados dos processos avaliativos;

III - o respeito à identidade e à diversidade de instituições e de cursos;

IV - a participação do corpo discente, docente e técnico-administrativo das instituições de educação superior, e da sociedade civil, por meio de suas representações. (Brasil, 2004).

De maneira complementar, o parágrafo único do mencionado artigo estabelece que resultados da avaliação se constituirão referencial básico dos processos de regulação e supervisão da educação superior, nos quais estão envolvidos o “(...) credenciamento e a renovação de credenciamento de instituições de educação superior, a autorização, o reconhecimento e a renovação de reconhecimento de cursos de graduação.” (BRASIL, 2004).

É importante, contudo, destacar que o Artigo $3^{\circ}$, inciso I, da Lei do SINAES, atribui a avaliação das instituições de educação superior o objetivo traçar o perfil dessas instituições por meio do plano de desenvolvimento institucional. A partir dessas orientações, podemos inferir que a intenção da desta Lei se destina a estabelecer diretrizes para a avaliação das instituições da educação superior aludindo o caráter público aos procedimentos institucionais, a apresentação de dados e resultados, bem como a ampla participação, por meio de representações, de todos os segmentos da comunidade acadêmica e da sociedade civil. Por fim, ressalta especialmente a função do planejamento e da avaliação nos processos e alcance resultados e eficazes para a educação superior.

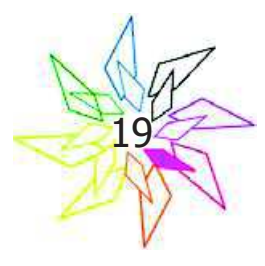




\section{O Plano de desenvolvimento institucional (PDI) da UNEB}

Considerando o entendimento concernente ao processo de planejamento aqui exposto, o Plano de Desenvolvimento Institucional (PDI) se constitui em um dos principais instrumentos que integram a gestão da instituição Universitária, no caso específico Universidade do Estado da Bahia (UNEB), concebido com a finalidade de orientar, apresentar subsídios, difundir informações e orientar a instituição, no sentido de alcançar suas expectativas, objetivos e metas.

O PDI se consubstancia no princípio democrático da transparência e da participação, bem como se constitui de maneira flexível, conforme preceitua a característica do processo de planejamento, capaz de ajustar-se às constantes e inerentes mudanças do ambiente acadêmico e suas estruturas organizacionais.

Cabe salientar que a Resolução n ${ }^{0}$ 10/2002 do Conselho Nacional de Educação, dispõe que o período de vigência do PDI corresponde a cinco anos, e seu conteúdo expõe à sociedade a filosofia da instituição, sua missão, as diretrizes pedagógicas (PIMENTA, 2016). O propósito consiste em fornecer contribuições que apoiem a tomada de decisão no âmbito da gestão, com suas particularidades regionais, culturais, política e acadêmicas, próprias do modelo multicampi da UNEB.

A rigor, o PDI segue um roteiro recomendado pelo Ministério da Educação (MEC), ao tempo em que, define também seu próprio percurso, considerando sua realidade institucional, vinculação ao Sistema Estadual de Educação da Bahia e, por fim, sua integração global ao Sistema de Avaliação do Ensino Superior (Sinaes), criado pela Lei no 2004 e ao Sistema Nacional de PósGraduação (SNPG) (PIMENTA, 2016).

O referido Plano também respalda o processo de avaliação institucional, por força da mencionada lei, bem como é parte integrante do processo de recredenciamento da universidade, e dos processos de reconhecimento dos cursos.

Reconhecemos, portanto, a importância de tal documento para o dinâmico funcionamento de uma instituição universitária, o qual não deve se constituir em um documento frio, utilizado apenas para o processo de recredenciamento, mas um documento presente no cotidiano da ação universitária sujeito a alterações em decorrência de metas atingidas ou contingências legais e mesmo financeiras. 
Com efeito, o PDI se apresenta como um documento que pode subsidiar a tomada de decisão ante a um cenário onde se constata a expansão da educação superior na Bahia e o acirramento da competitividade na oferta desse nível de ensino, sobretudo, com a entrada no Brasil e na Bahia de grupos empresarias internacionais. De outra parte, pode fornecer elementos aos gestores para lidar com um cenário de ameaças e constantes mudanças e, sobretudo, enfrentar as medidas restritivas para a gestão das despesas e controle dos gastos de custeio, investimento e de pessoal estabelecidas pelo governo estadual, a partir dos Decretos 15.924/15 e 16.417/15.

\section{Conexões entre o PDI e o programa de gestão ProGest e os processos ava- liação institucional}

Quando se trata de estabelecer um planejamento para a gestão de uma Universidade cuja atuação produz impactos nos territórios do estado da Bahia, como é o caso da Uneb, é importante estabelecer com clareza seus objetivos institucionais e identificar os meios adequados para alcançá-los. Sob esse ponto de vista, um planejamento dessa natureza representa constituir um instrumento capaz de tornar intenções de caráter mais abrangente em ações exequíveis.

A atualização dos instrumentos de planejamento no âmbito da Uneb levou em consideração algumas orientações contidas nas diversas políticas voltadas para a educação superior em âmbito nacional e estadual, entre as quais destacamos: o Plano Nacional de Educação (PNE, 2014 - 2024), o Plano Nacional de Pós-Graduação (PNPG, 2011 - 2020), Programa de Extensão Universitária (Proext), o Sistema Nacional de Avaliação da Educação Superior (Sinaes), o Sistema Nacional de Pós-Graduação (SNPG), o Plano Estadual de Educação (PEE, 2016 - 2026), o Plano Plurianual do Estado da Bahia (PPA, 2016 - 2019), o Estatuto e Regimento Interno da Uneb e o Plano de Ações Prioritárias (2014 - 2017).

Se considerarmos a estrutura clássica de planejamento, podemos verificar que esta se coaduna às necessidades de gestão de instituições de grande porte, como a Uneb, ou seja, são caracterizadas pelos níveis estratégico, tácito e operacional.

Deste modo, a ideia de estabelecer conexões entre planejamento e a avaliação se delineia a partir do desenvolvimento dos níveis mencionados, isto é:

- Nível estratégico, utilizado para avaliar o ambiente externo e interno, a fim de maneira a indicar um rumo para a instituição em grandes metas. No caso da UNEB, o Plano de Desenvolvimento Institucional - PDI (2017-2022) cumpre esse propósito;

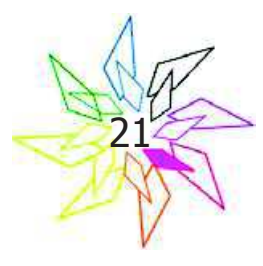


- Nível tático atua sob a estrutura do planejamento estratégico para abordar as principais ações das áreas específicas, necessárias ao alcance das metas. Nesse caso, tem o propósito de sinalizar as ações necessárias para o alcance das metas estabelecidas no PDI, indicando um sentido de atuação para a gestão universitária, por meio ProGest (2018-2021);

- Nível operacional refere-se a aquilo que cada unidade de gestão deverá organizar e realizar as tarefas específicas e necessárias para realizar as ações do ProGest, e que podem levam à consecução das metas PDI (2017-2022).

Desta forma, o ProGest foi estruturado em treze dimensões e sessenta e duas metas, correlatas ao PDI da Universidade. As referidas metas, por sua vez, se constituem em 149 ações, vinculadas a um setor responsável, setores articulados e a previsão orçamentária para o período de 2018 a 2021. No que se refere aos processos de avaliativos, destacamos que estes incendem sobre as ações estabelecidas pelas unidades de gestão contidas no ProGest, a partir de atividades específicas, descrição do produto, ações orçamentárias, percentual alcançado da meta e indicadores de acompanhamento. Para tal fim, a Uneb desenvolveu um Sistema de Planejamento e Gestão Universitária (SPGU), a partir do qual se poderá obter uma visão macro do desenvolvimento do PDI e do ProGest, conforme figura a seguir procura demonstrar.

Figura 1: Articulação entre PDI e ProGest: dimensões, metas e ações, acompanhado pelo Sistema de Planejamento e Gestão universitária - SPGU

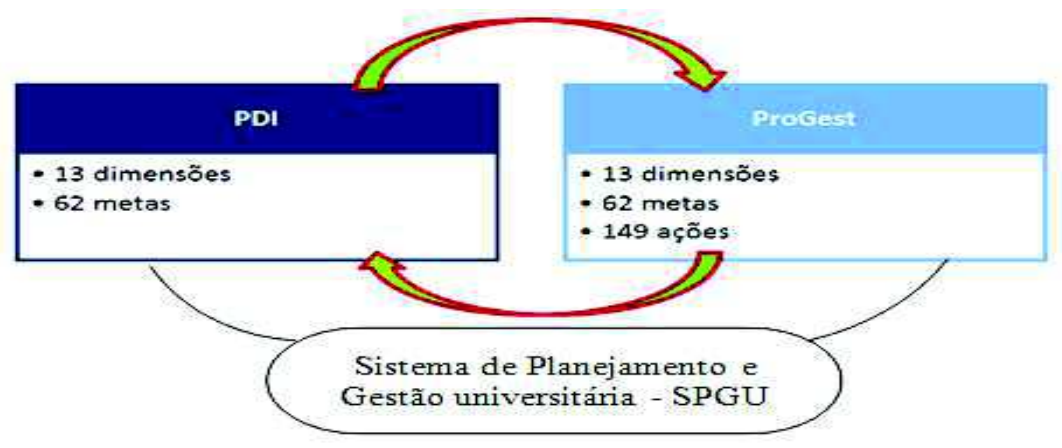

Fonte: Adaptado de Programa de Gestão ProGest 2018 - 2021.

Cabe salientar que as dimensões do PDI e suas metas foram incorporadas ao ProGest. A partir dessa estrutura estratégica de planejamento, foram definidas ações táticas com indicação 
de responsáveis, articulação necessária e previsão orçamentária, de modo a permitir seu acompanhamento por meio de indicadores de avaliação institucional.

Esse processo vidou evidenciar a correlação entre o PDI, o ProGest, bem como indicar o sentido mais amplo de ações localizadas em setores específicos, apoiados pela aplicação de processos avaliativos. Assim, as dimensões estabelecidas no PDI/Uneb, procuram se alinhar ao Decreto 9235/2017, conforme quadro a seguir.

Figura 1: Metas Previstas no PDI em Relação às Ações Constantes do PROGEST por dimensão de Atuação da Universidade

\begin{tabular}{|l|c|c|}
\hline \multicolumn{1}{|c|}{ Dimensão } & Metas (PDI) & Ações (Progest) \\
\hline Graduação & 6 & 13 \\
\hline Pós-graduação & 4 & 10 \\
\hline Extensão & 5 & 8 \\
\hline Educação à distância & 3 & 8 \\
\hline Pcsquisa c inovação & 4 & 11 \\
\hline Internacionalização & 2 & 8 \\
\hline Gestão e organização & 7 & 20 \\
\hline Gestão de Pessoas & 7 & 11 \\
\hline Infraestrutura & 5 & 9 \\
\hline Planejamento e Avaliação Institucional & 8 & 27 \\
\hline Assistência estudantil & 4 & 4 \\
\hline Responsabilidade social e ações afirmativas & 4 & 14 \\
\hline Comunicação c Cultura & 3 & 6 \\
\hline Total & $\mathbf{6 2}$ & $\mathbf{1 4 9}$ \\
\hline
\end{tabular}

Fonte: Elaborado pelos autores, 2018..

Com efeito, a avaliação cumpre o papel de intermediar e acompanhar o desenvolvimento e execução do planejamento voltado para a gestão da Universidade, por meio do Sistema de Planejamento e Gestão Universitária (SPGU), demarcando os possíveis avanços e sugerindo ajustes, caso necessário. 
De outra parte, é importante considerar os ciclos avaliativos que envolvem a Universidade. Estes dizem respeito à Instituição e seus cursos de graduação, por meio do Sistema Nacional de Avaliação do Ensino Superior (SINAES), e aos cursos de pós-graduação stricto sensu, através da Avaliação do Sistema Nacional de Pós-graduação (SNPG) realizada pela Coordenação de Aperfeiçoamento de Pessoal de Nível Superior (CAPES).

Esses ciclos compõem a vida universitária e coexistem com os processos de avaliação interna, como forma de oferecer elementos de base para a condução da gestão universitária, bem como da educação superior.

\section{Considerações finais}

Conforme mencionamos, esse artigo pretendeu descrever as medidas adotadas pela Uneb no sentido de atualizar o Plano de Desenvolvimento Institucional, Constituir o Programa de Gestão Universitária e estabelecer mecanismos de acompanhamento por meio da criação do Sistema de Planejamento e Gestão Universitária (SPGU).

Procuramos estabelecer nexos entre o planejamento e a avaliação no contexto da educação superior, destacando a experiência adotada pela Uneb, relatando as fases de construção, execução, acompanhamento e avaliação do Plano de Desenvolvimento Institucional das Instituições.

Cabe salientar que a despeito de se constituir em uma experiência inovadora no âmbito da gestão desta Universidade, acreditamos que o seu delineamento inicial foi bem sucedido. Compreendemos, todavia, que há um longo percurso a percorrer. O PDI se constitui em um planejamento estratégico, no qual se requer constantes ajustes de rota e adaptações necessárias ao alcance de suas metas.

Cabe destacar a importância do envolvimento, especialmente, dos gestores e a participação da comunidade universitária, extraindo os elementos essências para a tomada de decisão nos assuntos concernentes as suas unidades universitárias.

A descrição da experiência inovadora da Uneb no sentido de articular o Plano de Desenvolvimento Institucional, com o Programa de Gestão Universitária e criar um Sistema de Planejamento e Gestão Universitária (SPGU), cria uma expectativa de enfrentar o problema do planejamento desarticulado e com conotações de mera formalidade. Nossa compreensão se apoia 
na possibilidade real de utilizar os mecanismos já desenvolvidos como meio para subsidiar a tomada de decisão, a prestação de contas e o controle social.

Cabe sublinhar, que há alguns desafios a superar, ou seja, a disponibilização de mecanismos de planejamento e avaliação, não é suficiente para o sucesso do planejamento da gestão universitária, se desacompanhados de uma compreensão sobre as macro políticas para a universidade.

A efetivação do processo de planejamento associado à avaliação pressupõe, no nosso ponto de vista, estabelecer metodologias de execução descomplicadas, acessíveis e identificadas com as áreas de atuação de cada unidade universitária. Cabe reconhecer a importância do PDI, do ProGest e da avaliação como mecanismos capazes de qualificar as ações da Uneb, bem como de outras instituições de ensino que desejem conhecer essa experiência.

\section{REFERÊNCIAS}

BRASIL. Lei no 9.394, de 20 de dezembro de 1996. Estabelece as diretrizes e bases da educação nacional. Brasília-DF: Congresso Nacional, 1996. Disponível em: <http://www.planalto.gov.br/ ccivil_03/Leis/L9394.htm>. Acesso em: julho 2018.

Lei $n^{\circ} 10.861$ de 14.04.2004. Institui o Sistema Nacional de Avaliação da Educação Superior - SINAES e dá outras providências. Diário Oficial da República Federativa do Brasil, Poder Executivo, Brasília, DF, 15 abr. 2004.

Conselho Nacional de Educação. Resolução no 10/2002, de 11 de março de 2002. Dispõe sobre o credenciamento, transferência de mantença, estatutos e regimentos de instituições de ensino superior, autorização de cursos de graduação, reconhecimento e renovação de reconhecimento de cursos superiores, normas e critérios para supervisão do ensino superior do Sistema Federal de Educação Superior.

GIL, Antonio Carlos. Como elaborar projetos de pesquisa. 4a ed. São Paulo: Atlas, 2002.

LUZ, Érico Eleutério da. Controladoria corporativa. 2. ed. Curitiba: InterSaberes, 2014.

MATIAS-PEREIRA, J. Manual de gestão pública contemporânea. São Paulo: Atlas, 2010

PARENTE FILHO, José. Planejamento estratégico na educação. Brasília DF. Ed. plano, 2001.

p/UTais Salvador, v. 3, n. 2, p. 12-26, abr./ago. 2018 
PIMENTA. Lídia Boaventura. UNIVERSIDADE: características dos instrumentos da gestão. In: Universidades Estaduais e Financiamento da Educação Superior no Bahia. FIALHO, Nadia Haje (Org.). Universidade do Estado da Bahia. EDUNEB: Salvador, 2016

ROESCH, Sylvia Maria Azevedo. Projetos de Estágio e de Pesquisa em Administração: guia para estágios, trabalhos de conclusão, dissertações e estudos de caso. 2. ed. São Paulo: Atlas, 1999.

SILVA, Lino Martins da. Contabilidade Governamental. Um Enfoque Administrativo da Nova Contabilidade Pública. $9^{\text {a }}$ ed. São Paulo: Atlas, 2011.

VALERIANO, Dalton L. Gerência em Projetos: Pesquisa, Desenvolvimento e Engenharia. São Paulo: Makron Books, 1998. 